\title{
The Roles of Administrators in Aboriginal Schools: A Case Study in a Malaysian State
}

\author{
Norwaliza A. Wahab, Ramlee B. Mustapha, and Abdul Razaq Ahmad
}

\begin{abstract}
This case study examined the roles of administrators toward the educational achievement of 'Orang Asli' or 'Aboriginal' students. Two Aboriginal primary school administrators were purposely selected as informants. In order to understand the "voices" of these administrators, interviews and observations were conducted at the sites. A modified GPILSEO model was used as the theoretical framework in which only four out of the seven constructs of the model were utilized, i.e., goal, pedagogy, institution and leadership. The interview was audio-taped, transcribed and checked for emerging themes. The findings show that the school administrators have flexible targets, encouraged teachers to use fun methods of teaching and learning, and assessed teachers periodically. However, the respondents were less satisfied on equipment and infrastructure of the school. Leadership of aboriginal schools should be more committed and possess proactive and responsive attitudes toward the students, teachers, and the community. A major implication of the study is that the school administrators should play a significant role as a change agent in order to enhance the quality of education for the Orang Asli students.
\end{abstract}

Index Terms-Aboriginal schools, GPILSEO model, administrators, pedagogy, Malaysia.

\section{INTRODUCTION}

Along with the rapid progress and transformation of the country to achieve Vision 2020, awareness of the importance of education is increasing, especially among the young generation. Thus, the society holds educational institutions responsible in providing a quality education for its adolescents and youth.

Hence to achieve excellence in any school, the administrators play a major role in ensuring the success of the organization. The effort to pursue and achieve excellence in education lies in the hands of the school administrators [1] including the Aboriginal schools in Malaysia. Without education, Aboriginal people may retain in poverty and may lag behind the other communities. Due to their poor academic achievement, they remain one of the poorest in the country [2].

Aboriginal people of the Peninsular Malaysia or widely known as Orang Asli (Original People) consists of eighteen unique tribes with their own language, custom and lifestyle. However, the image of Orang Asli among the mainstream Malaysians was stereotyped as backward, poor, lazy, and uneducated. The Orang Asli schools in mostly remote

Manuscript received October 15, 2014; revised January 15, 2015.

Norwaliza A. Wahab and Abdul Razaq Ahmad is with the Universiti Kebangsaan, Malaysia (e-mail: lyzaalogan@gmail.com).

Ramlee B. Mustapha is with the Universiti Pendidikan Sultan, Idris. villages and settlements are generally less equipped, without full-day electricity, lacking of clean water, and having problems with internet line and the teaching staff. The most serious issue in Orang Asli schools is the achievement of Aboriginal students in their academic subjects as compared to the mainstream students. Thus, it is critical to probe deeper into the malaise of the Indigenous primary schools from the voices of the school administrators.

The accountability of principals has been understood to establish and maintain good relationships among teachers, representing the role of instructional leader, and exhibiting budgeting practices [3]. School leadership role is closely linked to the efforts to enhance the quality of teaching and learning in schools. Often this process involves the implementation of innovative educational programs aimed at improving the performance of students especially for indigenous students who are lagging behind in education. Research shows that high dropouts among Orang Asli children have become a grave issue as it was reported nearly $34 \%$ of those who had completed their primary schooling did not pursue their studies at the secondary level. The lack of interests in academic subjects at schools might be one of the plausible reasons [4], [5].

As a leader or manager of the school, particularly in Orang Asli school, school administrator is expected to play a significant role, including in enhancing the image of the school, conducting staff development activities and building good relationships between schools and the surrounding communities [6]. The role of school administrators is seen as a determinant of success (or failure) in the implementation of education programs in Orang Asli schools in particular.

\section{RESEARCH AND PROBLEM BACKGROUND}

The Orang Asli of Peninsular Malaysia comprises of 18 ethnic subgroups classified under the three major groups: Negrito, Senoi and Proto Malay [7]. They make up only $0.6 \%$ of the total Malaysian population. Senoi is the largest ethnic group constituting about $55 \%$ of the total population of Orang Asli, followed by the Proto Malays and the Negritos at $42 \%$ and $3 \%$, respectively. Meanwhile, the level of achievement in education of Orang Asli students is among the lowest as compared to the other ethnic groups in Malaysia. A study conducted by JAKOA found that the lack of enrolment of Orang Asli students at both secondary schools and also in higher education is due to the low level of schooling [8]. If one hundred Orang Asli students entering year one (Grade 1), only six students will be continuing up to Form 5 (Grade 11). The total of 94 percent of these students cannot be traced either graduated or not [9]. This bleak 
situation may be due to the school environment, community, family and teachers.

Hasan Mat Nor [10] asserts the school administrators play a critical role in determining the performance and quality of the school especially in Orang Asli schools that lead to dropout in primary and secondary school levels [11]. In addition, there are indications that show a significant dropout during Years 4 and 5 of Orang Asli pupils at the primary school [12]. Among the factors that contribute to the dropout of the Orang Asli students include the limited educational facilities such as computers, internet and the lack of specialized indigenous training for teachers to handle Orang Asli students [13]. The lack of knowledge of the teachers and the school administrators about indigenous culture may distort the interaction and might create discomfort between teachers and pupils [14]. Difficulty to interact due to the poor mastery of Malay language among the Orang Asli students causes poor understanding of the lesson and it leads to failure in the academic subjects. Teaching a second language to non-native students need careful consideration in terms of planning, implementation, and assessment. Indigenous people who are closely related to the spirits of the land, flora and fauna, they are more receptive to a more natural way of learning and not too formal and this aspect should be considered by the school.

School administrators should find appropriate model of teaching and learning for aboriginal students. Teachers should be trained in indigenous pedagogy. In order to investigate deeper on the problems faced by Orang Asli pupils in selected schools in Pahang, this case study used the GPILSEO model as a theoretical framework to help us improve our understanding of the necessities required by Orang Asli pupils in raising their educational achievement. Due to the limited indigenous research that obtained qualitative data from school administrators, this case study embarked of reaching the voices and reflections of the school headmasters regarding their utmost client: the Orang Asli pupils.

\section{RESEARCH CONCEPTUAL FRAMEWORK}

The conceptual framework of this study was based on a model developed by Bishop and O'Sullivan in reviewing the achievements of Maori's education in New Zealand [15]. The GPILSEO model was originally implemented in New Zealand on the Maori schools. It is an effective model in raising the educational achievement of Maori students in New Zealand as they participated actively in the schools and society since 2001 through the program of Te Kotahitanga [16]. The GPILSEO model comprises seven constructs, namely, Goals, Pedagogy, Institutions, Leadership, Spread, Evidence and Ownership. Due to limited space to discuss all the seven constructs, this study has focused only the four constructs. These four constructs were carefully selected based on their priority and the scope of this article. In school, generally, these four variables are considered important due to their pertinent roles especially from the school administrators' perspective.

The purpose of this study was to explore the roles of school administrators in the selected Orang Asli schools. The state of education of Orang Asli pupils were analyzed according to the school administrators' perspectives. The conceptual framework of the study was presented in Fig. 1.

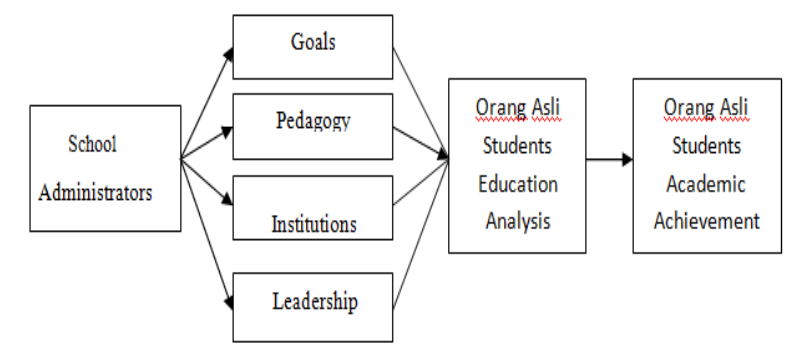

Fig. 1. The conceptual framework.

\section{RESEARCH METHODOLOGY}

This study used the case study method. Data obtained in this study were gathered through semi-structured interviews and observations. Because this research explored the voices and reflections of the informants, a qualitative approach allowed for more in-depth analysis and greater freedom to analyze unforeseen occurrences during the process. "A qualitative methods facilitate study of issues in depth and detail" [18]. In this study, the respondents were purposivefully selected. Sample selection was based on the criteria that they taught at the Orang Asli students' school, aged between 35 to 50 years and has been working as Orang Asli school administrator for at least three years. These two informants were coded as SA1 and SA2.

Location of this study involved two primary Orang Asli schools located in the state of Pahang. The state of Pahang was selected because Pahang has the largest number of Orang Asli in Peninsular Malaysia. This study utilized interview and, "...interviewing may be defined simply as a conversation with a purpose. Specifically, the purpose is to gather information..." [19]. Protocol questions of this interview were constructed in the form of open questions where the respondents are free to express their views. However, the interviewer guided the discussion so that it may not deviate from the original issue.

\section{FINDINGS AND DISCUSSIONS}

Based on GPILSEO model, four out of seven critical domains were selected due to their importance. They are: a) roles of school administrators based on goals, b) roles of school administrators based on pedagogy, c) roles of school administrators based on institutions, and d) roles of school administrators regarding leadership. The results of the study are as follows:

\section{A. Administrators' Roles Based on Goals}

In a centralized system, Malaysia's Ministry of Education has set the umbrella goals for the schooling system in this country. However, each school could set their own goals. In terms of Orang Asli's school, one of the respondents (SA1) asserted that goals should be set based on the reality of the school. He asserts:

“...in my school, if the pupils can read and write, I am 
happy with that...but at the District Education Office and State Education Department, they set higher targets because they said a low target will get a low result...(SA1)."

Based on the excerpt, it shows that there could be a discrepancy between the school's goals and the goals set by the District and State Education Departments. The first informant SA1 believe that a realistic goal is far more important that an ideal goal. In addition, the school administrators of Orang Asli's school should be optimistic about their school as shared by another informant (SA2):

"...since 2007 this school has achieved a good percentage of the UPSR (national assessment) for Orang Asli school. In 2010 , we received $10 \%$ passing rate and in 2011, we hope to have students who may score at least $3 A$."

Thus, the voices and reflections of these two school administrators reaffirm the roles of school administrators to set realistic goals for their own schools and to be optimistic about the future success of their students. However, other studies show that schools need to set a higher target to ensure the students obtain good results and improve their academic achievement [20].

\section{B. Administrators' Roles Based on Pedagogy}

Pedagogy is an important element in learning. Based on the conversation with SA1, knowing and understanding the psyche and the culture of Orang Asli is an utmost important for non-Orang Asli teachers who teach Orang Asli pupils. As SA1 states,

"...with these students, if we are angry, they will not come to school...we must always give encouragement and show that we understand them... (SAI)."

The other school administrator (SA2) suggested an effective way to teach Orang Asli pupils is to include music to add more fun in the learning process because they tend to get bored easily.

"...students want music during their lessons, I have been here for a very long time already, I understand their behaviors well. I always advise all my teachers to teach in a way that can excite the students because they quickly get bored... (SA2)."

Based on the observations in a class, the school administrator (SA2) creatively asked the Orang Asli students to sing a song to keep them active and participate in the learning process. This shows that the teacher must be creative and innovative in a classroom so that the teaching will always relevant and suitable with the culture and context [21], [22]. The findings also in line with the assertion that students love interesting and culturally relevant pedagogy rather than overly dependent on textbook or chalk and talk method [23]. Gay [24] states that a relevant and effective learning process is based on knowledge of students' culture, past experience and their learning styles. In the nutshell, one of the critical roles of the school administrators is to nurture creativity and innovative pedagogy among their teachers. The way the Orang Asli kids learnt is different than urban kids as they learn through the indigenous language, arts, ritual, folklore and taboos which do not have a fixed syllabus and timetable of learning [25]. The pedagogy of teaching, which follows rigid curriculum in the national school system, practiced by the teachers has placed the Orang Asli students in an awkward position [26]. In case of Orang Asli school, indigenous pedagogy is a must for every teacher who intend to teach at an aboriginal school.

\section{Administrators' Roles Based on Institution}

In this study, institution refers to the Orang Asli schools that were involved in the research. Both school administrators SA1 and SA2 said that the facilities at the school are barely adequate for the purpose of teaching and learning but they are in a sorry state. For instance, informant SA1 says,

“...basically we have basic classroom facilities but mostly in poor condition. We have furniture, however they are in terrible condition. There is no hall like in the urban schools to conduct programs. We have resource center to accommodate the student' needs to read and borrow books but the number of books are limited. And the worst thing is we don't have enough funding to buy new equipment. Actually, we have applied to have a computer lab with several computers. When we get a computer lab, we need a computer technician...but we don't know when we will get the computer lab." (SA1).

This finding is in line with some studies that found that most rural schools lack of facilities, face financial problems and arrive at the stage where it is difficult to sustain the schools as compared to the urban schools [27], [28]. However, recorded observations in the present study show that the headmaster's office and general office are equipped with facilities such as computers, LCD projector, fax machine and internet but some of the facilities are not functioning well. As SA2 admits,

"...these facilities are very important because the location of school is far from the town..." and they are critical to "...facilitate communication, especially with the education office but they did breakdown from time to time..." (SA2)

In this context, the role of the school administrators is to make sure the equipment and infrastructure are in place. Unfortunately, in this case, the state of the infrastructure in these two Orang Asli schools is rather unsatisfactory. But the school administrators are not giving up, they keep trying to obtain the facilities every year. Efforts were undertaken to improve the quality of life of the Orang Asli through socio-economic programs which included the provision of education and skills training, infrastructure facilities, electricity and water supply.

\section{Administrators' Roles Based on Leadership}

One of the critical domains in Orang Asli education is school leadership. Both informants said that they monitor the teaching of their teachers periodically. These were the statements of the informant SA1 regarding the aspect of leadership,

"...as the school administrator, I have prepared the observation (assessment) form to observe the teachers teaching and learning in class. I have prepared the 
assessment form, one copy for the teacher and then the marks will be given for them. Thus, the teachers will know their performance either good or not based on the marks given. Normally, they will be observed twice a year..." (SA1).

Besides monitoring the teacher's competency in teaching, students' attendance is also critical. Truancy among Orang Asli pupils is quite significant especially during fruit season. As informant SA2 states,

"It is more important to monitor the students' attendance to school. As long as students' attendance is good, we feel happy because [we believe] they can learn".

Thus, another critical role of school administrator is to monitor the quality of teaching and the students' attendance. The school management has prepared the assessment form to be used to monitor the teachers' teaching in the classroom. The observation was conducted according to the given date. Monitoring of teachers is an indicator of effective school leadership. Several research supported the practice because it could enhance teachers' quality [29], [30]. In the same token, the school administrators should also be concerned about the students' attendance. Good school will always have almost full attendance.

\section{SUMMARY}

Based on the interviews with two selected school administrators, we can conclude that there are certain roles played by effective school managers in order to enhance the quality of the schools especially the aboriginal schools. The role of administrative is very important in increasing the effectiveness of teaching and learning in formal education. In terms of implications, this study to some extent, provides critical knowledge on the strengths and the weaknesses of the Orang Asli education by looking into the four main aspects in GPILSEO model.

The data show that the school administrators have to be flexible in terms of the goals setting for their school. However, voices from the interviews and observations also show that there are some negative situations that could be attributed to Orang Asli lack of interest in education. Such as, elements related to effective pedagogy in the classroom should be reexamined by the school administrators. For the purpose of tailoring the syllabus according to the learning style of the Orang Asli students, the Ministry of Education Malaysia and the United Nations Children's Fund (UNICEF) have a plan to introduce and incorporate the Orang Asli culture into the teaching and learning aids.

Other issues such as lack of proactive leadership, poor assessment for teachers, and lack of available facilities are pertinent to be highlighted by the school leadership in order to create a more conducive learning environment. Johari and Nazri [31] suggested that experienced teachers and basic facilities are important in improving the academic performance of the Orang Asli students. Other than that, the basic infrastructure namely the learning materials also need to be improved and provided by the authority so that it could enhance the teaching and learning process of the Orang Asli students. In addition, supports from various parties should be provided to enhance the Orang Asli students' interest to come to school (to increase their sense of belonging and ownership). The findings of this research are also expected to provide clearer picture for the school administrators in terms of their roles in managing effectively Orang Asli schools.

\section{REFERENCES}

[1] H. Mahmood, Leadership and School Effectiveness, Kuala Lumpur: Dewan Bahasa dan Pustaka, 1993.

[2] I. Nadchatram. (2007). Folklore inspiration to improve Malaysian Orang Asli children's literacy', UNICEF Malaysia. [Online]. Available: http://www.unicef.org/malaysia/media_7099.html

[3] L. Lashway, "Who's in charge? The accountability challenge," Principal Leadership, vol. 1, no. 3, pp. 8-13, 2000.

[4] R. Mustapha et al., "Human capital development of orang asli youth: supportive and suppressive factors," Procedia Social and Behavioral Sciences, vol. 7, pp. 592-600, 2010.

[5] A. R. Ahmad and Z. M. Jelas, Indigenous People: Socioculture and Education Perspective, Bangi: National University of Malaysia Publisher, 2009.

[6] M. Ibrahim, Pengetua Sekolah: Menangani Isu Dan Cabaran Kepimpinan, Kumpulan Budiman Sdn. Bhd: Kuala Lumpur, 2001.

[7] C. Nicholas, "Integration and modernization of the Orang Asli: the impact on culture and identity," Paper presented at the 1st International Conference on the Indigenous People, Kuala Lumpur, 2005,

[8] C. Nicholas, "The state of Orang Asli education and its problems," Consultancy report presented at Human Rights Commission of Malaysia (SUHAKAM), Kuala Lumpur, 21 July 2006.

[9] Nicholas. (2007). Orang Asli after 50 Years of Independence. [Online]. Available: http://www.coac.org

[10] H. M. Nor, "Research on Orang Asli dropouts at primary school level," Anthropology and Social Department National University of Malaysia, 1997.

[11] T. Crooks, K. Hamilton, and R. Caygill. (2000). New Zealand's National Education Monitoring Project: Maori Student Achievement 1995-2000. [Online]. Available: http://nemp.otago.ac.nz/i_probe.htm/

[12] H. M. Nor, "Research on Orang Asli dropouts at primary school level," Anthropology and Social Department National University of Malaysia, 1997.

[13] A. Castagno and B. Braybo, "Culturally responsive schooling for Indigenous youth: A review of the literature," Review of Educational Research, vol. 78, no. 4, pp. 941-993, 2008.

[14] R. Bishop and D. O'Sullivan, “Taking a reform project to scale: Considering the conditions that promote sustainability and spread of reform," The National Institute for Research Excellence in Maori Development and Advancement Unpublished Manuscript, 2005.

[15] R. A. Bishop and T. Glynn, Culture Counts: Changing Power Relations in Education, Palmerston North: Dunmore Press, 1999.

[16] R. Walker, Ka Whawhai Tonu Matou: Struggle without End, Auckland: Penguin Books, 1990.

[17] M. Q. Patton, "Qualitative Research and Evaluation Methods," Sage Publications, 2002.

[18] B. L. Berg, Qualitative Research Methods for the Social Sciences, $5^{\text {th }}$ ed., Boston: Pearson, 2004.

[19] H. Timperley et al., "Teacher professional learning and development: Best evidence synthesis iteration," Wellington: New Zealand Ministry of Education, 2007

[20] T. R. Gushey, "Does it make a difference? Evaluating Professional Development," Educational Leadership, vol. 59, no. 6, pp. 45-51, 2002.

[21] M. Y. Abdullah, S. A. Rashid, R. I. R. L. Ahmad, Z. Mohamed, A. S. Ambotang, and S. Sharif, "Teachers' pedagogy knowledge," Kota Kinabalu: Universiti Malaysia Sabah, 2008.

[22] G. B. Esquivel, "Teacher behaviors that foster creativity," Educational Psychology Review, vol. 7, no. 2, pp. 185-202, 1995

[23] S. Nieto, What Keeps Teachers Going? New York: Teachers College Press, 2003.

[24] G. Gay, Culturally Responsive Teaching: Theory, Research and Practice, New York: Teachers College Press, 2000.

[25] N. P. Karubi, S. C. Goy, and B. W. K. Wong, "The Temiar and the invisible wisdom of taboo: Survival strategy and sustainability," in Proc. the egional Conference of Local Knowledge: Retracing Tradition for a Sustainable Future, Langkawi, Malaysia, 2011. 
[26] C. Nicholas, Orang Asli: Rights, Problems, Solutions, Suruhanjaya Hak Asasi Manusia, 2000.

[27] P. Burdette, "Response to intervention as it relates to early intervening services: Recommendations (department of education cooperative agreement No. H326F050001)," Alexandria, VA: National Association of State Directors of Special Education, 2007.

[28] D. F. Mellard and E. Johnson, A Practitioner's Guide to Implementing Response to Intervention, Thousand Oaks, CA: Corwin Press, 2008.

[29] K. Kamaruddin, Siri Pengurusan Pendidikan-Ke Arah Penguasaan Pelajar Dinamik, Kuala Lumpur: Teks Publishing Sdn. Bhd. 1989.

[30] P. Hallinger, "Leading educational change: Reflections on the practice of instructional and transformational leadership," Cambridge Journal of Education, vol. 33, no. 3, pp. 329-351, 2003.

[31] T. Johari and M. Nazri, "Bagaimana kanak-kanak Orang Asli gagal di sekolah," Jurnal Pengajian Umum Asia Tenggara, Bil, vol. 8, pp. 51-76, 2007.

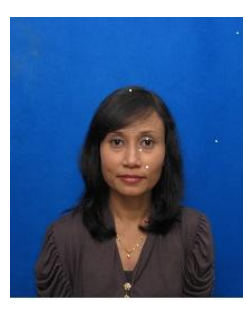

Norwaliza Abdul Wahab was born in Negeri Sembilan, Malaysia in 1971. She gained a master degree in educational sociology and she earned doctoral degree also in educational sociology from the National University of Malaysia. Currently, she is a counselor at Seri Pagi Secondary School, Seremban, Negeri Sembilan and a part time lecturer at Open University of Malaysia teaching psychology. Her research interests are mainly on guidance and counseling, indigenous studies and indigenous learning of minority groups and aboriginal people. She has conducted research on sociology especially on administrative roles, schools of aboriginal students and aboriginal communities. She has published more than 15 articles and book chapters, mainly in Malay language. Dr. Norwaliza Abdul Wahab is a member of the Asian Academic Society for Vocational Education and Training (AASVET) since 2012.

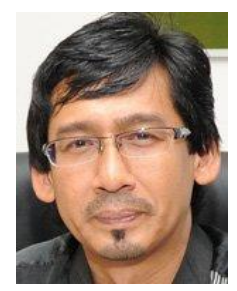

Ramlee B. Mustapha is a professor and the former dean of the Faculty of Technical and Vocational Education, Universiti Pendidikan Sultan Idris (UPSI) (Sultan Idris Education University). He is the secretary-general of the Asian Academic Society for vocational education and training (AASVET). He is an expert in vocational education and training and human resource development especially in the Pacific Rim and East Asian region. His research interests lie in leadership and curriculum development, inventive thinking, experiential learning, higher technical-vocational education, indigenous learning of minority groups (special needs students and Orang Asli - Malay Aborigines) and multicultural human resource development. He has written over 100 articles and 6 books in technical-vocational education and human resource development. His latest books include Technical and Vocational Education (2014) (published by Sultan Idris Education University), He is the Chief Editor for the Journal of Asian Vocational Education and Training. He also served as international editorial board member for International Journal for Vocational Education and Training (United States). He was also an associate editor for International Journal of Learning (Australia). He is a member in professional associations such as International Vocational Education and Training Association (IVETA), ACTE (American Career and Technical Education), Pi Delta Kappa (USA), and Malaysian Vocational Association. Dr. Ramlee Mustapha holds a professional degree in chemical engineering (BSChE) from University of Alabama, USA. His first master degree in educational administration (M.Ed) from Eastern New Mexico University, USA and his second master degree in industrial technology (M.Sc) from Purdue University, USA. He earned a doctoral degree in technical and vocational education (Ph.D) also from Purdue University, USA.

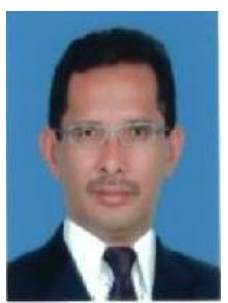

Abdul Razaq Ahmad is an associate professor at the Department of Educational Methodology and Practice, Faculty of Education, the National University of Malaysia. He is an expert in educational sociology, adult education and history of education. His research interests are mainly on indigenous population, minority groups and aboriginal communities. He has written many articles and books on indigenous issues. Dr. Abdul Razaq Ahmad gained a master degree in educational sociology from the National University of Malaysia and earned a doctoral degree in adult education from University of Malaya. 